\title{
Subclassification of pathologically organ-confined (pT2) prostate cancer does not significantly predict postoperative outcomes in Korean males
}

\author{
Min Ho Lee ${ }^{1}\left(\mathbb{D}\right.$, Sangchul Lee ${ }^{2}$, Sung Kyu Hong ${ }^{2}$, Seok-Soo Byun ${ }^{2}$, Sang Eun Lee ${ }^{2}$ (1) \\ 'Department of Urology, Gyeongsang National University Changwon Hospital, Gyeongsang National University School of Medicine, Changwon, ${ }^{2}$ Department of \\ Urology, Seoul National University Bundang Hospital, Seoul National University College of Medicine, Seongnam, Korea
}

Purpose: We evaluated the prognostic association of pT2 subclassification with the oncological outcomes in patients with prostate cancer (PCa) who underwent radical prostatectomy (RP) in South Korea.

Materials and Methods: We retrospectively reviewed 3,529 patients who underwent RP for pathologically organ-confined PCa between 2003 and 2017 at Seoul National University Bundang Hospital. We analyzed the differences in the rates of biochemical recurrence (BCR), overall survival (OS), and cancer-specific survival (CSS) between pT2 substages.

Results: According to the 2002 TNM staging system, 362 (15.3\%) and 2,000 patients (84.5\%) had T2a (involving one-half or less of a unilateral lobe) and T2c (involving bilateral lobes) diseases. Four patients $(0.2 \%)$ had T2b (involving more than one-half of a unilateral lobe) disease and none of them developed BCR. The mean follow-up period was $8.4 \pm 3.7$ years and 175 patients $(7.4 \%)$ had BCR. On multivariable analysis, $\mathrm{pT} 2$ subclassification ( $\mathrm{pT2a} / \mathrm{b}$ vs. $\mathrm{pT2c}$ ) was not a significant predictor of $\mathrm{BCR}(\mathrm{p}=0.224)$ or OS $(p=0.311)$. Biochemical disease-free survival $(p=0.091)$, OS $(p=0.502)$, and CSS $(p=0.063)$ showed no significant difference between pT2 substages.

Conclusions: Our study revealed that the PT2 subclassification of PCa in Korean males provided no value for predicting BCR, OS, and CSS after RP, which agrees with recently reported results based on the updated 8th version of the American Joint Committee on Cancer (AJCC) TNM staging system.

Keywords: Pathology; Prognosis; Prostate neoplasms; Prostatectomy; Recurrence

This is an Open Access article distributed under the terms of the Creative Commons Attribution Non-Commercial License (http://creativecommons.org/licenses/by-nc/4.0) which permits unrestricted non-commercial use, distribution, and reproduction in any medium, provided the original work is properly cited.

\section{INTRODUCTION}

A well-established cancer staging system is essential for therapeutic planning and prognostication. The first clinical staging system for prostate cancer (PCa) was developed by Whitmore [1] and adopted in 1992 [2]. In that system, T2
PCa was defined as a prostate-confined palpable tumor that could be subclassified into three categories: T2a (involving one-half or less of a unilateral lobe), T2b (involving more than one-half of a unilateral lobe), or T2c (involving bilateral lobes). The 1997 TNM staging system combined all cases with unilateral disease as T2a and bilateral disease as T2b

Received: 15 July, 2019 - Accepted: 2 September, 2019

Corresponding Author: Sang Eun Lee (iD https://orcid.org/0000-0003-1729-1118

Department of Urology, Seoul National University Bundang Hospital, Seoul National University College of Medicine, 82 Gumi-ro 173beon-gil, Bundang-gu, Seongnam 13620, Korea

TEL: +82-31-787-7341, FAX: +82-31-787-4057, E-mail: selee@snubh.org 
[3]. However, some studies revealed that the 1992 version was superior for predicting the outcomes of T2 disease [4,5], which led to a revision back to the three categories in the 2002 TNM staging system [6]. Unfortunately, there remains controversy regarding the subclassification of pathological T2 disease, with approximately 66\% of United States and Canadian Academy of Pathology members agreeing to omit the p'T2 substage at their 98th meeting [7] and some studies indicating that $\mathrm{p}$ T2b disease did not exist $[8,9]$. Recent studies have also indicated that the subclassification of pT2 disease is not a useful prognostic factor [10,11].

Organ-confined PCa was recently integrated as pT2 in the 8th edition of the American Joint Committee on Cancer (AJCC) staging system [12,13]. However, this update was not based on level I evidence and large studies are needed to evaluate this update. Therefore, we retrospective examined a large single-center population of Korean males who underwent radical prostatectomy (RP) for pathologically organconfined PCa. The patients' pT2 subclassifications were evaluated to determine whether they could be used to predict biochemical recurrence (BCR), cancer-specific survival (CSS), and overall survival (OS).

\section{MATERIALS AND METHODS}

\section{Patient selection}

This study's retrospective protocol was approved by the appropriate Institutional Review Board (Seoul National University Bundang Hospital, approval number: 1907-552109), and the requirement for informed consent was waived. We retrospectively reviewed data from 3,529 patients who underwent RP for clinically localized PCa between November 2003 and November 2017. The RP procedures were performed by four different surgeons at our center. The present study included patients with pT2 disease, which was determined by a single pathologist at Seoul National University Bundang Hospital. Patients were excluded if they had received neoadjuvant hormone or radiation therapy (RT). And we did not conduct RT or androgen deprivation therapy (ADT) to patients who had positive margin until the occurrence of BCR. If the patients had BCR or recurrence by image study, we started RT or ADT to them. So, we regarded the margin positivity does not affects to the BCR. Totally, data from a total of 2,366 patients were analyzed. Radical retropubic prostatectomy (RRP) was commonly performed, with a gradual transition towards robot-assisted laparoscopic prostatectomy (RALP) over time. The RRP procedures were performed by a single experienced urologist, and the RALP procedures were performed by four experienced urologists according to the standard robotic surgery protocols at Seoul National University Bundang Hospital.

\section{Data collection}

The RP specimens were weighed and fixed in 10\% neutral formalin before being submitted to sequential pathological evaluations at Seoul National University Bundang Hospital, as previously described [9]. All specimens were originally evaluated by a single experienced pathologist using the 2002 TNM staging system. Based on the controversy regarding the existence of pT2b disease [9], and similar results at Seoul National University Bundang Hospital, we also reclassified the pT2 results based on the 1997 TNM staging system.

Serum prostate-specific antigen (PSA) levels were checked before every surgery, and $\geq 12$-core prostate biopsy was performed for patients with elevated serum PSA ( $\geq 3.0 \mathrm{ng}$ / $\mathrm{mL}$ ), suspicious findings during a digital rectal examination, and/or hypoechoic lesions detected during transrectal ultrasonography. Most patients underwent PSA testing at 4 to 6 weeks, every 6 months for 5 years, and then annually thereafter, with BCR defined as a PSA concentration of $\geq 0.2 \mathrm{ng} /$ $\mathrm{mL}$ according to the American Urological Association. Patients without BCR were censored based on their last followup at the urology department. Data regarding the causes of death (PCa or other causes) were obtained from the Statistics Korea.

\section{Statistical analysis}

Continuous variables were evaluated using the Student t-test or Mann-Whitney U test, and categorical variables were evaluated using the chi-squared or Fisher exact probability test. All analyses were performed using IBM SPSS software (version 25.0; IBM Corp., Armonk, NY, USA). Univariate and multivariate Cox proportional hazard models were used to identify factors that predicted the patients' outcomes. In addition, differences in BCR, CSS, and OS were evaluated using the Kaplan-Meier method and the log-rank test. All tests were two-sided and significant differences were identified based on p-values of $<0.05$.

\section{RESULTS}

Table 1 shows the characteristics of the 2,366 patients. According to the 2002 TNM staging system, 362 patients (15.3\%) had T2a disease and 2,000 patients (84.5\%) had T2c disease. Four patients (0.2\%) had T2b disease and none of them developed BCR. Thus, we analyzed the BCR, CSS, and OS outcomes according to the 1997 TNM staging system. The 
Table 1. The patients' characteristics

\begin{tabular}{|c|c|c|c|}
\hline Variable & Total $(n=2,366)$ & $\mathrm{pT} 2 \mathrm{a} / \mathrm{b}(\mathrm{n}=366[362 / 4])$ & $\mathrm{pT} 2 \mathrm{c}(\mathrm{n}=2,000)$ \\
\hline Age (y) & $65.6 \pm 6.9$ & $65.0 \pm 7.0$ & $65.7 \pm 6.9$ \\
\hline Body mass index $\left(\mathrm{kg} / \mathrm{m}^{2}\right)$ & $24.3 \pm 2.6$ & $24.5 \pm 2.7$ & $24.3 \pm 2.6$ \\
\hline Preoperative PSA (ng/mL) & $9.1 \pm 10.1$ & $8.3 \pm 7.0$ & $9.3 \pm 10.5$ \\
\hline Prostate weight (g) & $40.3 \pm 14.2$ & $43.6 \pm 16.7$ & $39.7 \pm 13.7$ \\
\hline Tumor volume (\%) & $11.7 \pm 1.1$ & $7.6 \pm 1.1$ & $12.5 \pm 1.7$ \\
\hline Follow-up (y) & $8.4 \pm 3.7$ & $8.6 \pm 2.8$ & $8.3 \pm 3.4$ \\
\hline \multicolumn{4}{|l|}{ Surgical type } \\
\hline RRP & $662(28.0)$ & $131(35.8)$ & $531(26.6)$ \\
\hline LRP & $36(1.5)$ & $10(2.7)$ & $26(1.3)$ \\
\hline RALP & $1,668(70.5)$ & $225(61.5)$ & $1,443(72.2)$ \\
\hline \multicolumn{4}{|l|}{ RP Gleason score } \\
\hline$\leq 6$ & $331(14.0)$ & $111(30.3)$ & $220(11.0)$ \\
\hline 7 & $1,907(80.6)$ & $233(63.7)$ & $1,674(83.7)$ \\
\hline$\geq 8$ & $128(5.4)$ & $22(6.0)$ & $106(5.3)$ \\
\hline Surgical margin positivity & $308(13.0)$ & $24(6.6)$ & $284(14.2)$ \\
\hline Perineural invasion & $1,516(64.1)$ & $164(44.8)$ & $1,352(67.6)$ \\
\hline Angiolymphatic invasion & $119(5.0)$ & $17(4.6)$ & $102(5.1)$ \\
\hline Tumor multifocality & $1,931(81.6)$ & $113(30.9)$ & $1,818(90.9)$ \\
\hline Biochemical recurrence & $175(7.4)$ & $20(5.5)$ & $155(7.8)$ \\
\hline Adjuvant therapy & $69(2.9)$ & $9(2.5)$ & $60(3.0)$ \\
\hline Hormone therapy & $41(1.7)$ & $4(1.1)$ & 37 (1.9) \\
\hline Radiation therapy & $38(1.6)$ & $6(1.6)$ & $32(1.6)$ \\
\hline Both & $10(0.4)$ & $1(0.3)$ & $9(0.5)$ \\
\hline
\end{tabular}

Values are presented as mean \pm standard deviation or number (\%).

$\mathrm{T} 2 \mathrm{a}$, involving one-half or less of a unilateral lobe; T2b, involving more than one-half of a unilateral lobe; T2c, involving bilateral lobe; PSA, prostate-specific antigen; RRP, radical retropubic prostatectomy; LRP, laparoscopic radical prostatectomy; RALP, robot-assisted laparoscopic prostatectomy; RP, radical prostatectomy.

Table 2. Multivariable Cox regression analysis of time to BCR and OS following RP in patient with pT2 disease

\begin{tabular}{|c|c|c|c|c|}
\hline \multirow{2}{*}{ Variable } & \multicolumn{2}{|c|}{ BCR } & \multicolumn{2}{|l|}{ OS } \\
\hline & Hazard ratio $(95 \% \mathrm{CI})$ & p-value & Hazard ratio $(95 \% \mathrm{Cl})$ & p-value \\
\hline PSA & $1.01(1.00-1.02)$ & 0.002 & Not assessed & \\
\hline Biopsy Gleason score & $1.69(1.37-2.09)$ & $<0.001$ & Not assessed & \\
\hline Surgical margin positivity & $2.99(2.19-4.10)$ & $<0.001$ & Not assessed & \\
\hline RP Gleason score & $1.59(1.20-2.10)$ & 0.001 & $1.75(1.23-2.48)$ & 0.002 \\
\hline Angiolymphatic invasion & $2.11(1.40-3.19)$ & $<0.001$ & $2.14(1.08-4.23)$ & 0.029 \\
\hline Prostate weight & Not assessed & & $1.02(1.01-1.03)$ & 0.002 \\
\hline pT2a/b vs. pT2c & $1.16(0.91-1.48)$ & 0.224 & $1.38(0.74-2.59)$ & 0.311 \\
\hline pT2a vs. pT2b/c & $1.29(0.80-2.09)$ & 0.299 & $1.34(0.74-2.51)$ & 0.363 \\
\hline
\end{tabular}

$\mathrm{BCR}$, biochemical recurrence; OS, overall survival; $\mathrm{RP}$, radical prostatectomy; $\mathrm{Cl}$, confidence interval; PSA, prostate-specific antigen; T2a, involving one-half or less of a unilateral lobe; $\mathrm{T} 2 \mathrm{~b}$, involving more than one-half of a unilateral lobe; $\mathrm{T} 2 \mathrm{c}$, involving bilateral lobe.

mean age at the time of $\mathrm{RP}$ was $65.6 \pm 6.9$ years and the mean preoperative PSA concentration was $9.1 \pm 10.1 \mathrm{ng} / \mathrm{mL}$. The mean follow-up period was $8.4 \pm 3.7$ years and 1,931 patients (81.6\%) had multifocal tumors. During the entire follow-up period, 175 patients $(7.4 \%)$ experienced BCR.

Table 2 shows the results of the multivariate analyses for predicting BCR and OS. The results revealed that BCR was independently predicted by surgical margin positivity (hazard ratio [HR], 2.99; 95\% confidence interval [C], 2.19-4.10) and pathological Gleason score (HR, 1.59; 95\% CI, 1.20-2.10). However, there was no significant difference in BCR when we compared $\mathrm{pT} 2 \mathrm{a} / \mathrm{b}$ versus $\mathrm{pT} 2 \mathrm{c}(\mathrm{p}=0.224)$ or $\mathrm{pT} 2 \mathrm{a}$ versus $\mathrm{pT} 2 \mathrm{~b} / \mathrm{c}(\mathrm{p}=0.299)$. Moreover, there was no significant difference in OS when we compared $p \mathrm{~T} 2 \mathrm{a} / \mathrm{b}$ versus $\mathrm{pT} 2 \mathrm{c}(\mathrm{p}=0.311)$ 
Table 3. Literature review of surgical outcomes for T2 disease according to the TNM staging systems

\begin{tabular}{|c|c|c|c|c|c|}
\hline Literature & $\begin{array}{l}\text { No. of } \\
\text { patients }\end{array}$ & Type & $\begin{array}{l}\text { Median } \\
\text { follow-up } \\
\text { (mo) }\end{array}$ & Conclusion & Proposal \\
\hline Han et al. (2000) [5] & 1,314 & Clinical & 72 & $\begin{array}{l}\text { OS for T2a92 superior than for } \\
\text { T2a97 }\end{array}$ & Revert to the 1992 version \\
\hline Cagiannos et al. (2002) [4] & 1,755 & Clinical & 26 & $\begin{array}{l}\text { RFS for T2a92 superior than for } \\
\text { T2b92 }\end{array}$ & 1992 was superior to 1997 \\
\hline Eichelberger and Cheng (2004) [8] & 369 & Pathological & - & The T2b02 subclass does not exist & $\begin{array}{l}\text { Eliminate the } \mathrm{T} 2 \mathrm{~b} \\
\text { subclassification }\end{array}$ \\
\hline Freedland et al. (2004) [14] & 1,606 & Pathological & 48 & $\begin{array}{l}\text { No significant difference in BCR } \\
\text { for } T 2 \mathrm{a} 97 \text { vs. } \mathrm{T} 2 \mathrm{~b} 97\end{array}$ & $\begin{array}{l}\text { Eliminate the T2b } \\
\text { subclassification }\end{array}$ \\
\hline Chun et al. (2006) [15] & 1,726 & Pathological & 24.4 & $\begin{array}{l}\text { No significant difference in } \mathrm{BCR} \\
\text { according to the } \mathrm{T} 2 \text { substages }\end{array}$ & Partin's pathological staging \\
\hline Hong et al. (2008) [9] & 372 & Pathological & - & Only 1 case of $\mathrm{T} 2 \mathrm{~b} 02$ & $\begin{array}{l}\text { Modification of the T2 } \\
\text { subclassification }\end{array}$ \\
\hline Nguyen et al. (2018) [11] & 15,305 & Pathological & 72 & $\begin{array}{l}\text { T2 substage is not a prognostic } \\
\text { factor }\end{array}$ & $\begin{array}{l}\text { The 8th AJCC edition should be } \\
\text { used }\end{array}$ \\
\hline
\end{tabular}

The TNM systems are abbreviated as 92 for the 1992 version, 97 for the 1997 version, 02 for the 2002 version, and 09 for the 2009 version. OS, overall survival; RFS, recurrence-free survival; BCR, biochemical recurrence; AJCC, American Joint Committee on Cancer.

Table 4. The patients' characteristics according to the operation date period

\begin{tabular}{|c|c|c|c|}
\hline Variable & 2003 to $2010(n=883)$ & 2011 to $2017(n=1,483)$ & $\mathrm{p}$-value \\
\hline Age (y) & $65.2 \pm 6.8$ & $65.9 \pm 7.0$ & 0.023 \\
\hline Body mass index $\left(\mathrm{kg} / \mathrm{m}^{2}\right)$ & $24.3 \pm 2.6$ & $24.3 \pm 2.7$ & 0.920 \\
\hline Preoperative PSA (ng/mL) & $8.7 \pm 8.6$ & $9.4 \pm 10.9$ & 0.074 \\
\hline Prostate weight (g) & $41.2 \pm 14.9$ & $39.9 \pm 13.8$ & 0.020 \\
\hline Tumor volume (\%) & $10.3 \pm 0.5$ & $12.6 \pm 1.3$ & 0.603 \\
\hline Surgical type & & & $<0.001$ \\
\hline RRP & $478(54.1)$ & $184(12.4)$ & \\
\hline LRP & $36(4.1)$ & $0(0.0)$ & \\
\hline RALP & $369(41.8)$ & $1,299(87.6)$ & \\
\hline T2 subclassification & & & 0.01 \\
\hline $\mathrm{pT} 2 \mathrm{a} / \mathrm{b}$ & $159(18.0)$ & $207(14.0)$ & \\
\hline pT2c & $724(82.0)$ & $1,276(86.0)$ & \\
\hline RP Gleason score & & & $<0.001$ \\
\hline$\leq 6$ & $264(29.9)$ & $67(4.5)$ & \\
\hline 7 & $583(66.0)$ & $1,324(89.3)$ & \\
\hline$\geq 8$ & $36(4.1)$ & $92(6.2)$ & \\
\hline Surgical margin positivity & $161(18.2)$ & $147(9.9)$ & $<0.001$ \\
\hline Perineural invasion & $434(49.2)$ & $1,082(73.0)$ & $<0.001$ \\
\hline Angiolymphatic invasion & $60(6.8)$ & $59(4.0)$ & 0.003 \\
\hline Tumor multifocality & $690(78.1)$ & $1,241(83.7)$ & 0.001 \\
\hline Biochemical recurrence & $105(11.9)$ & $70(4.7)$ & $<0.001$ \\
\hline
\end{tabular}

Values are presented as mean \pm standard deviation or number (\%).

PSA, prostate-specific antigen; RRP, radical retropubic prostatectomy; LRP, laparoscopic radical prostatectomy; RALP, robot-assisted laparoscopic prostatectomy; RP, radical prostatectomy; T2a, involving one-half or less of a unilateral lobe; T2b, involving more than one-half of a unilateral lobe; T2c, involving bilateral lobe.

or $\mathrm{p}$ T2a versus $\mathrm{p} T 2 \mathrm{~b} / \mathrm{c}(\mathrm{p}=0.363)$. To compare with our results, we reviewed the 7 literatures from 2000 to 2018 in Table 3 $[4,5,8,9,11,14,15]$.

Table 4 shows the differences of basic characteristics ac- cording to the enrolled period. During 2003 to 2010 year, the patients who had RRP (54.1\%) were more than RALP (41.8\%). However, during 2011 to 2017 year, more patients had RALP (87.6\%) than RRP (12.4\%). Additionally, the surgical outcomes 


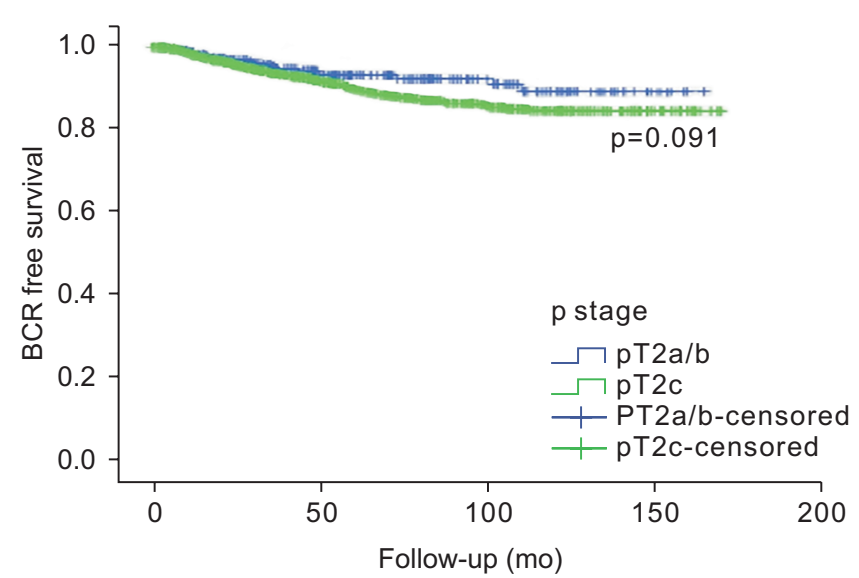

Fig. 1. Kaplan-Meier curves for biochemical recurrence $(B C R)$ free survival according to $\mathrm{pT} 2 \mathrm{a} / \mathrm{b}$ and $\mathrm{pT} 2 \mathrm{c}$ prostate cancer. $\mathrm{T} 2 \mathrm{a}$, involving one-half or less of a unilateral lobe; $T 2 b$, involving more than one-half of a unilateral lobe; $\mathrm{T} 2 \mathrm{c}$, involving bilateral lobe.

and pathologic reports showed worse results in the early period group than did the recent period group.

Among patients with pT2a/b PCa, 20 patients (5.4\%) developed BCR. Fig. 1 shows that the rates of biochemical disease-free survival (bDFS) were $93.3 \%$ at 5 years and $89.4 \%$ at 10 years. Among patients with pT2c PCa, 155 patients (7.8\%) developed BCR and the bDFS rates were slightly and nonsignificantly lower at 5 years (89.9\%) and at 10 years (84.6\%) $(p=0.091)$. Fig. 2 shows that there were no significant differences in OS when we compared pT2a/b versus pT2c PCa at 5 years (96.8\% vs. $95.3 \%$ ) and at 10 years (93.1\% vs. 91.4\%) (logrank $\mathrm{p}=0.502$ ). There was also no significant difference in CSS when we compared the pT2 substages at 5 years $(99.4 \%$ vs. $99.9 \%$, $\mathrm{p}=0.063)$.

\section{DISCUSSION}

Implementation of PSA screening tests has led to increasingly early detection of $\mathrm{PCa}$, with Korean patients being diagnosed at lower stages based on their biopsy findings and post-RP pathological reports [16]. At the same time, the AJCC TNM staging system has been repeatedly revised from the 1992 version to the current AJCC 8th version in 2017 [17], and there remain controversies that are related to the unavailability of high-quality data and related recommendations [8]. The present study evaluated a large cohort of Korean males with PCa (mean follow-up of $>8$ years), and confirmed that the pT2 subclassification may not help improve prognostication in terms of BCR, OS, and CSS, which agrees with the findings from several previous studies [9,15,18,19]. In this context, Antunes et al. [10] have reported no significant differences in surgical outcomes, BCR rates

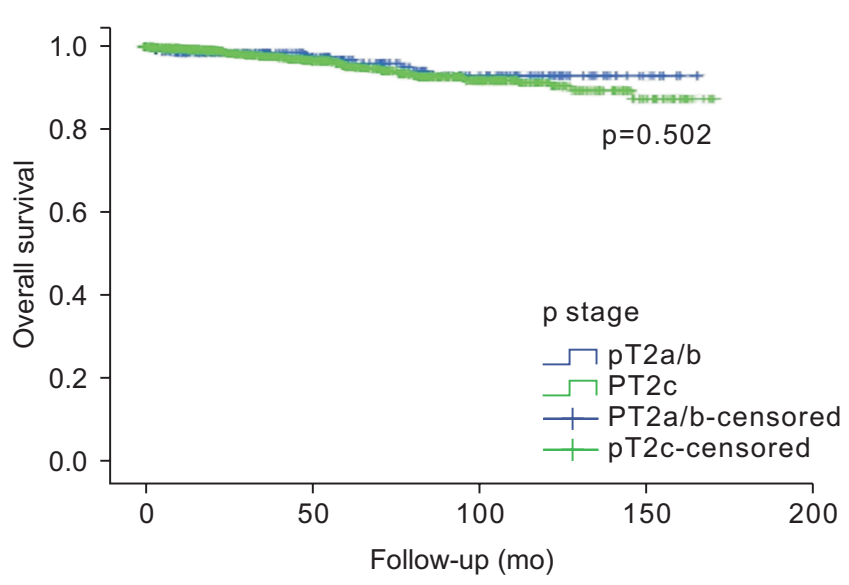

Fig. 2. Kaplan-Meier curves for overall survival according to $p T 2 a / b$ and $\mathrm{pT} 2 \mathrm{c}$ prostate cancer. $\mathrm{T} 2 \mathrm{a}$, involving one-half or less of a unilateral lobe; $T 2 b$, involving more than one-half of a unilateral lobe; $T 2 c$, involving bilateral lobe.

( $11.3 \%$ for $\mathrm{pT} 2 \mathrm{a} / \mathrm{b}$ vs. $18.2 \%$ for $\mathrm{pT} 2 \mathrm{c}, \mathrm{p}=0.2)$, or OS $(92.5 \%$ vs. $93.6 \%, p=0.2$ ). Nguyen et al. [11] have also reported that the pT2 substage could not predict prognosis, and they recommended eliminating the pT2 substages from the revised system, based on the lack of significant differences in BCR $(p=0.4)$, CSS $(p=0.6)$, and OS $(p=0.3)$. Moreover, Freedland et al. [14] observed no significant difference in BCR between patients with unilateral and bilateral organ-confined $\mathrm{PCa}$, with approximately $81 \%$ of their patients having a pathological Gleason score of $\leq 6$. Chun et al. [15] also failed to detect a significant difference during a median follow-up of 24 months, with $62 \%$ of their patients having a pathological Gleason score of $\leq 6$. The present study confirms these findings with a longer mean follow-up ( $>8$ years) and a smaller proportion of patients with a Gleason score of $\leq 6(14.0 \%)$, which may help provide insight regarding cases with relatively aggressive pathological characteristics.

Eichelberger and Cheng [8] studied 369 totally embedded and serially sectioned RP specimens, with approximately $75 \%$ of the specimens involving pT2 disease (but no pT2b tumors) and 312 cases (85\%) exhibiting multifocality. The present study also included large proportions of multifocality (81.6\%) and perineural invasion (64.1\%), although we failed to detect significant differences in BCR or OS in the univariable and multivariable analyses. Nevertheless, we observed a significant difference in the risk of BCR according to the pre-RP and post-RP Gleason scores (HR, 1.69 vs. HR, $1.59 ; \mathrm{p}<0.001)$. Similarly, previous studies have indicated that the post-RP Gleason score is one of the strongest prognostic factors for patients with margin-negative pT2 $\mathrm{PCa}[14,18,19]$.

Wolters et al. [20] evaluated the prognostic value of index tumor size in cases of pT2 PCa, and Wise et al. [21] have 
reported that the index tumor volume had equal prognostic value relative to the total tumor volume. Unfortunately, the present study was unable to evaluate index tumor volume and there is no standard volume measurement technique. The importance of preoperative serum PSA concentration is also well recognized [22-24], although we found that it only marginally predicted the time to BCR (HR, 1.01; 95\% CI, $1.00-1.02 ; \mathrm{p}=0.002$ ).

The present study revealed relatively good outcomes in terms of BCR-free survival, OS, and CSS at 5 years and 10 years, which agrees with previously reported results. For example, Eggener et al. [25] reported that the 15-year risk of PCa-specific death was only $0.8 \%$ to $1.5 \%$ among 11,521 American patients with pT2 PCa. Two European studies also revealed 10-year CSS rates of $98 \%$ to $98.7 \%$ among patients who underwent TP for pT2 PCa [26,27]. These results indicate that patients who undergo RP for $\mathrm{pT} 2 \mathrm{PCa}$ tend to have clinically homogeneous characteristics and a good prognosis. However, the study enrolled period was more than 10 years, and there have been many developments in surgical techniques. In present study, the patients enrolled early period of study showed worse pathological outcomes including BCR.

This is the first limitations of this study. In close future, we will validate our results by further study according to the surgical techniques and it will strengthen the present study. Second, the retrospective single-center design is prone to misclassification, information bias, and missing data. Furthermore, Hong et al. [9] have reported that there are still differences in PSA screening and the detection of low-grade PCa between Asian and Western countries. However, the present study evaluated a relatively large sample of patients with prolonged follow-up, and we believe it is the first to evaluate whether the pT2 subclassification could be eliminated based on long-term surgical outcomes among Korean males.

\section{CONCLUSIONS}

The present study revealed that the pT2 subclassification of $\mathrm{PCa}$ in Korean males provided no value for predicting BCR, OS, and CSS after RP, which agrees with recently reported results based on the updated 8th version of the AJCC TNM staging system. Therefore, a more accurate risk stratification strategy is needed to optimize the surgical outcomes in patients with organ-confined PCa.

\section{CONFLICTS OF INTEREST}

The authors have nothing to disclose.

\section{AUTHORS' CONTRIBUTIONS}

Research conception and design: Sang Eun Lee and Min Ho Lee. Data acquisition: Sang Eun Lee, Sangchul Lee, Sung Kyu Hong, and Seok-Soo Byun. Data analysis and interpretation: Min Ho Lee. Statistical analysis: Min Ho Lee. Drafting of the manuscript: Sang Eun Lee and Min Ho Lee. Approval of the final manuscript: all authors.

\section{REFERENCES}

1. Whitmore WF Jr. Hormone therapy in prostatic cancer. Am J Med 1956;21:697-713.

2. Beahrs OH, Henson DE, Hutter RVP, Kennedy BJ; American Joint Committee on Cancer. Manual for staging of cancer. 4th ed. Philadelphia: J.B. Lippincott Company; 1992.

3. Fleming ID, Cooper JS, Henson DE, Hutter RVP, Kennedy BJ, Murphy GP, et al.; American Joint Committee on Cancer. AJCC cancer staging manual. 5th ed. Philadelphia: LippincottRaven; 1997.

4. Cagiannos I, Graefen M, Karakiewicz PI, Ohori M, Eastham JA, Rabbani F, et al. Analysis of clinical stage T2 prostate cancer: do current subclassifications represent an improvement? J Clin Oncol 2002;20:2025-30.

5. Han M, Walsh PC, Partin AW, Rodriguez R. Ability of the 1992 and 1997 American Joint Committee on Cancer staging systems for prostate cancer to predict progression-free survival after radical prostatectomy for stage T2 disease. J Urol 2000;164:89-92.

6. Greene FL, Page DL, Fleming ID, Fritz AG, Balch CM, Haller DG, et al.; American Joint Committee on Cancer. AJCC cancer staging manual. 6th ed. New York: Springer; 2002.

7. van der Kwast TH, Amin MB, Billis A, Epstein JI, Griffiths D, Humphrey PA, et al.; ISUP Prostate Cancer Group. International Society of Urological Pathology (ISUP) consensus conference on handling and staging of radical prostatectomy specimens. Working group 2: T2 substaging and prostate cancer volume. Mod Pathol 2011;24:16-25.

8. Eichelberger LE, Cheng L. Does pT2b prostate carcinoma exist? Critical appraisal of the 2002 TNM classification of prostate carcinoma. Cancer 2004;100:2573-6.

9. Hong SK, Han BK, Chung JS, Park DS, Jeong SJ, Byun SS, et al. Evaluation of pT2 subdivisions in the TNM staging system for prostate cancer. BJU Int 2008;102:1092-6.

10. Antunes HP, Parada B, Carvalho J, Eliseu M, Jarimba R, Olivei- 
ra R, et al. Prognostic value of subclassification (pT2 stage) of pathologically organ-confined prostate cancer: confirmation of the changes introduced in the 8th edition of the American Joint Committee on Cancer (AJCC) staging system. Arch Ital Urol Androl 2018;90:191-4.

11. Nguyen DP, Vertosick EA, Sharma V, Corradi RB, Vilaseca A, Takeda T, et al. Does subclassification of pathologically organ confined ( $\mathrm{pT} 2$ ) prostate cancer provide prognostic discrimination of outcomes after radical prostatectomy? J Urol 2018;199:1502-9.

12. Paner GP, Stadler WM, Hansel DE, Montironi R, Lin DW, Amin MB. Updates in the eighth edition of the tumor-nodemetastasis staging classification for urologic cancers. Eur Urol 2018;73:560-9.

13. Fine SW. Evolution in prostate cancer staging: pathology updates from AJCC 8th edition and opportunities that remain. Adv Anat Pathol 2018;25:327-32.

14. Freedland SJ, Partin AW, Epstein JI, Walsh PC. Biochemical failure after radical prostatectomy in men with pathologic organ-confined disease: pT2a versus pT2b. Cancer 2004;100:1646-9.

15. Chun FK, Briganti A, Lebeau T, Fradet V, Steuber T, Walz J, et al. The 2002 AJCC pT2 substages confer no prognostic information on the rate of biochemical recurrence after radical prostatectomy. Eur Urol 2006;49:273-8; discussion 278-9.

16. Gleason DF, Mellinger GT. Prediction of prognosis for prostatic adenocarcinoma by combined histological grading and clinical staging. J Urol 1974;111:58-64.

17. Brierley JD, Gospodarowicz MK, O'Sullivan B, Wittekind C. TNM classification of malignant tumours. 8th ed. Chichester: Wiley-Blackwell; 2017.

18. Kordan Y, Chang SS, Salem S, Cookson MS, Clark PE, Davis R, et al. Pathological stage T2 subgroups to predict biochemical recurrence after prostatectomy. J Urol 2009;182:2291-5.

19. Caso JR, Tsivian M, Mouraviev V, Polascik TJ, Moul JW. Patho- logical T2 sub-divisions as a prognostic factor in the biochemical recurrence of prostate cancer. BJU Int 2010;106:1623-7.

20. Wolters T, Roobol MJ, van Leeuwen PJ, van den Bergh RC, Hoedemaeker RF, van Leenders GJ, et al. Should pathologists routinely report prostate tumour volume? The prognostic value of tumour volume in prostate cancer. Eur Urol 2010;57:8219.

21. Wise AM, Stamey TA, McNeal JE, Clayton JL. Morphologic and clinical significance of multifocal prostate cancers in radical prostatectomy specimens. Urology 2002;60:264-9.

22. D'Amico AV, Whittington R, Malkowicz SB, Schultz D, Blank $\mathrm{K}$, Broderick GA, et al. Biochemical outcome after radical prostatectomy, external beam radiation therapy, or interstitial radiation therapy for clinically localized prostate cancer. JAMA 1998;280:969-74.

23. D'Amico AV, Cote K, Loffredo M, Renshaw AA, Chen MH. Pretreatment predictors of time to cancer specific death after prostate specific antigen failure. J Urol 2003;169:1320-4.

24. Boorjian SA, Karnes RJ, Rangel LJ, Bergstralh EJ, Blute ML. Mayo Clinic validation of the D'amico risk group classification for predicting survival following radical prostatectomy. J Urol 2008;179:1354-60; discussion 1360-1.

25. Eggener SE, Scardino PT, Walsh PC, Han M, Partin AW, Trock BJ, et al. Predicting 15-year prostate cancer specific mortality after radical prostatectomy. J Urol 2011;185:869-75.

26. Mortezavi A, Sulser T, Robbiani J, Drescher E, Disteldorf D, Eberli D, et al. Long-term oncologic outcome of an initial series of laparoscopic radical prostatectomy for clinically localized prostate cancer after a median follow-up of 10 years. Clin Genitourin Cancer 2016;14:290-7.

27. Isbarn H, Wanner M, Salomon G, Steuber T, Schlomm T, Köllermann J, et al. Long-term data on the survival of patients with prostate cancer treated with radical prostatectomy in the prostate-specific antigen era. BJU Int 2010;106:37-43. 